\title{
DESIGN AND FABRICATION OF FIXTURE FOR MACHINING VE - PUMP COVER IN VERTICAL MILLING MACHINE
}

\author{
Rudresha $\mathbf{N}^{1}$, Vijay Kumar $\mathbf{M}^{2}$ \\ ${ }^{1}$ Department of Industrial Engineering \& Management, JSS Academy of Technical Education, Bengaluru - 560060 \\ ${ }^{2}$ Department of Industrial Engineering \& Management, JSS Academy of Technical Education, Bengaluru - 560060
}

\begin{abstract}
In Mass Production to produce high quality products and reduce the cost by avoiding defect manufacturing practices also for increasing the efficiency of the process, interchangeability of components, accuracy, reduced manufacturing lead time and easy assembly in automobile sectors, Fixtures are preferred since from so many years. The Fixture should support the work piece while manufacturing according to specified dimensions and tolerances it must be approximately located and clamped. Designing fixture for pump cover or other contour surfaces importance is given to the support blocks and clamps also cost is other criteria it should not affect the total cost of the product. According to specified dimensions and requirement the Fixture is Designed and Fabricated. Modeling is done using Unigraphics NX.
\end{abstract}

Keywords: CAD - Computer aided design, CAM - Computer Aided Manufacturing, JIT - Just in Time manufacturing.

\section{INTRODUCTION}

The worlds demand to manufacture goods growing at staggering rate. Industries have to respond these dynamic demands sometimes radical ways to producing products, from evaluation of CAD \& CAM for today's manufacturing concepts. FMS, JIT and SPC are the art of manufacturing has undergone many dramatic and advance changes. These changes have created a dire need for more cost effective work holding devices. As many manufacturing companies shift their interests towards a zero part inventory systems to keep less cost more profit, the need of efficient \& cost effective work holders is becoming more important.

The part, not the process, is the primary and main consideration in work holding; throughout the text fundamental tool design principles are simplicity and economy. The effective work holder must save money in manufacturing component. Finally the fixture must be cost effective as possible; also it must have the capacity to perform all intended functions. Project work carried out at CPPL. Work was concentrated on the department of manufacturing. The design and fabrication work fixture process deals with all features related to design aspects.

\section{METHODS FOR DESIGNING FIXTURES}

While designing fixtures we have to follow number of distinct activities:

1. Fixture planning.

2. Layout design for fixture.

3. Fixture element design.

4. Tool body design. Etc...

The fig. 1 gives the list of material sequence, although they can develop in parallel. $* * *$

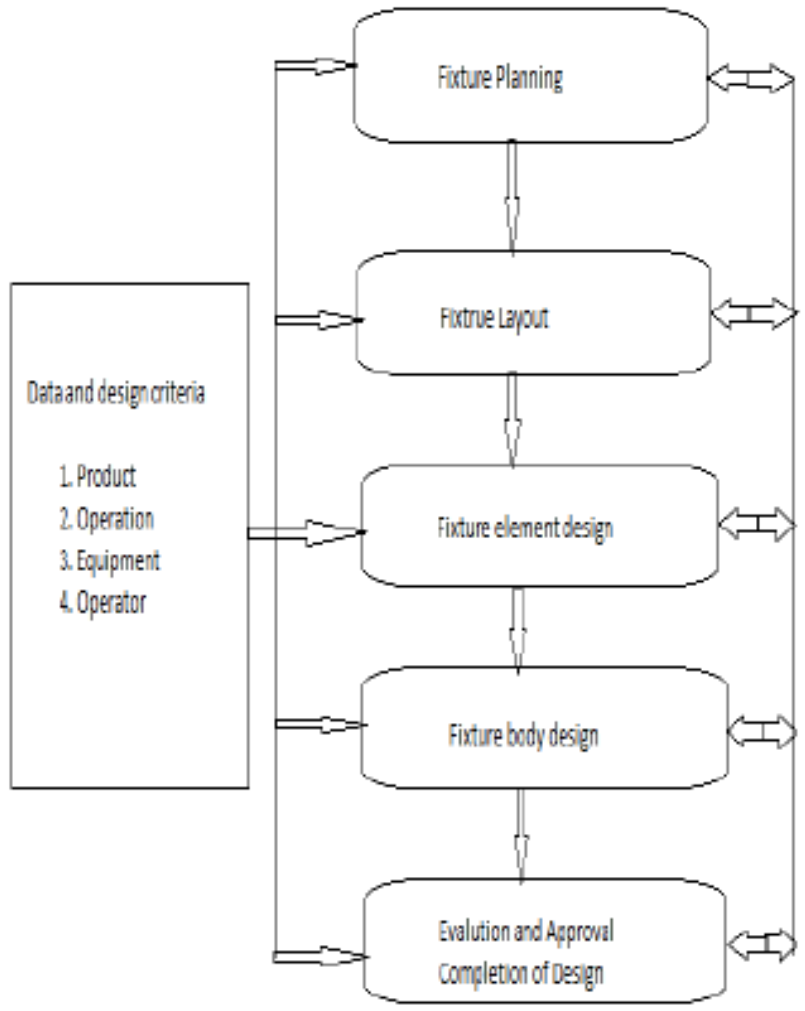

Fig 1 various aspects of fixture design 


\section{Component}

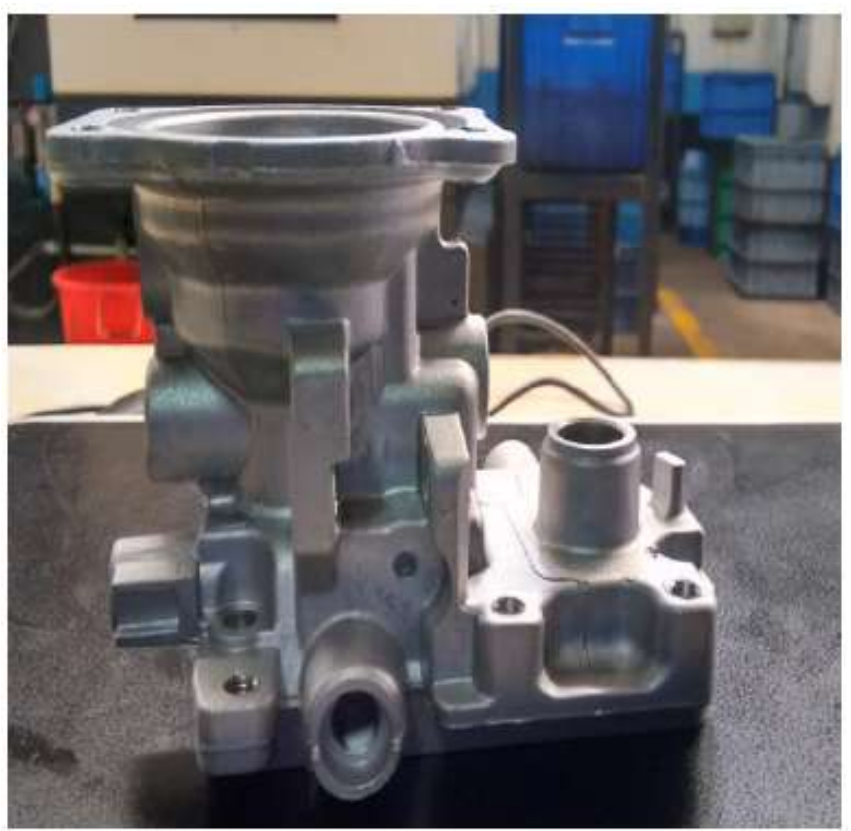

Fig 2 Pump Cover

Cast iron body of pump cover component which is supplied from Emmel vheelars Kolhapur.

\section{Assembled 3D View of Fixture}

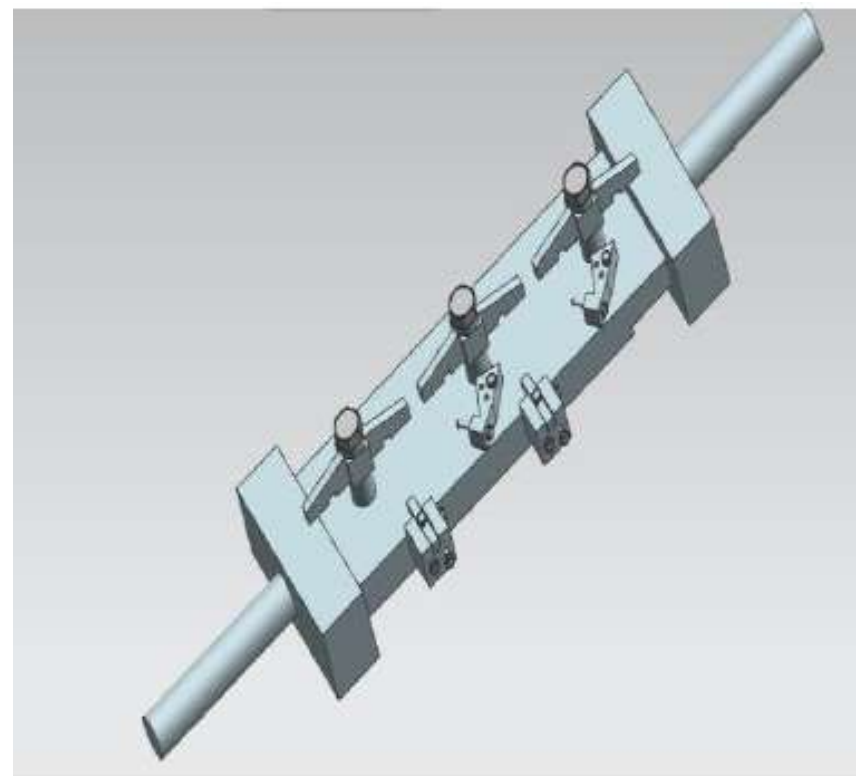

Fig 3. 3D View of Fixture Assembly

Fixture consist of seven components those are Base, Wedges, Support blocks, Key, Bush and Bolts. These are Modelled and assembled in Unigraphics NX software.

\section{Fabricated Fixture is used in Machine for}

\section{Manufacturing the Component}

Using Trial and error method the fixture is fabricated and also Manufacturing process started using this Fixture.

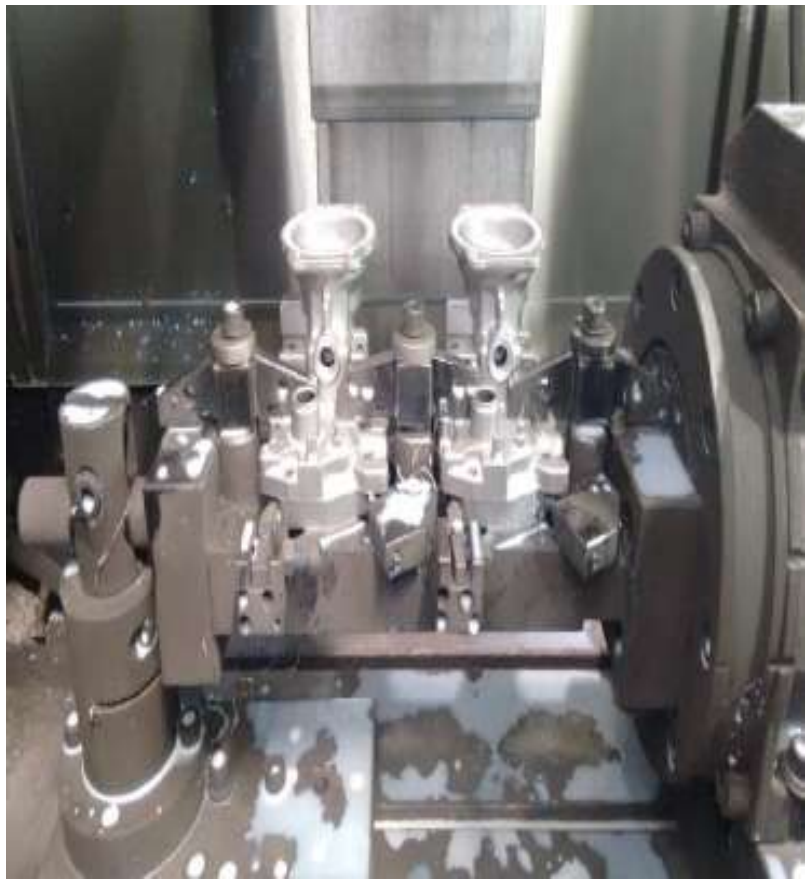

Fig 4 Fabricated Fixture is used in machine for Manufacturing

\section{CONCLUSION}

As a result of this project work the pump cover component is machined in vertical milling machine by fixing two components at a time, which will reduce the lead time, also the accuracy of the machining is increases. Using this Designed Fixture the required dimensions are obtained accurately. As the cost of Fixture is very less and it is more suitable for small scale industries.

The main purpose of the Project is higher productivity, reduce time, required dimensions of the component should be obtained, less human effort and mass production. These are achieved successfully.

\section{REFERENCES}

[1]. P H joshi, "Jigs and fixture manual" Tata McGraw Hill [2]. Asada H. by kinematic analysis of work part fixture for flexible assembly with automatically reconfigurable fixtures. IEEE Journals of robotics and automation, 1(2), pp. 86-94. 1985

[3]. Fuh, and Nee A.Y.C Verification and optimisation of work holding schemes for fixture design. Journal of design and manufacturing 4, pp. 307-318. 1994.

[4]. Roe, Joseph Wickham (1916), English and American Tool Builders, New Haven, Connecticut: Yale University Press, LCCN 16011753. Reprinted by McGraw-Hill, New York and London, 1926 (LCCN 27-24075); and by Lindsay Publications, Inc., Bradley, Illinois, (ISBN 978-0-91791473-7).

[5]. Roe, Joseph Wickham (1918), The mechanical equipment: Volume 3: Factory Management Course 3, New York, NY, USA: Industrial Extension Institute, Inc, LCCN 18006648. 
[6]. Pease, William (1952), "An automatic machine tool",

Scientific American $187 \quad$ (3): $101-$

115,doi:10.1038/scientificamerican0952-101, ISSN 00368733.

[7]. Woodbury, Robert S. (1972) [1960], History of the Milling Machine. In Studies in the History of Machine Tools, Cambridge, Massachusetts, USA, and London, England: MIT Press, ISBN 978-0-262-73033-4, LCCN 72006354. First published alone as a monograph in 1960.

[8]. Baida, Peter (May-June 1987), "Eli Whitney's Other Talent", American Heritage 38 (4), retrieved 2010-11-29.

[9]. American Precision Museum (1992), "Rudolph Bannow (1897-1962)", Machine Tool Hall of Fame (American Precision Museum), retrieved 2011-01-01.

[10]. Encyclopædia Britannica (2011), diesinking, retrieved 2011-01-02 